\title{
Expression of Survivin in Patients With Refractory Rheumatoid Arthritis in a Chinese Population
}

\author{
Xian Ming LONG, ${ }^{1,2}$ Jin Wei CHEN, ${ }^{1}$ Wen Jing WANG, ${ }^{1}$ Jia WANG ${ }^{1}$ \\ ${ }^{1}$ Department of Rheumatology, The Second Xiangya Hospital, Central South University, Changsha, China \\ ${ }^{2}$ Department of Rheumatology, The First Affiliated Hospital of Soochow University, Suzhou, China
}

\begin{abstract}
Objectives: This study aims to investigate whether the expression of survivin is associated with refractory rheumatoid arthritis (RA) among Chinese patients.

Patients and methods: We evaluated the expression of survivin in serum and synovial tissues in 60 patients of RA and 20 healthy controls. Rheumatoid arthritis patients were divided into three groups: 20 patients in the untreated group, 20 patients in the treatment-responsive group and 20 patients in the treatment refractory group. Serum concentrations of survivin in four groups were measured by enzyme-linked immunosorbent assay. Clinical features and laboratory test results including disease duration, complete blood count, erythrocyte sedimentation rate, C-reactive protein, rheumatoid factor and anti-cyclic citrullinated peptide antibody were recorded. Expression levels of survivin in synovial tissue of all 51 samples were tested by immunohistochemical technique.

Results: The survivin level was significantly higher in the refractory group than healthy controls $(270.04 \pm 23.03 \mathrm{pg} / \mathrm{ml} \mathrm{vs.} 116.68 \pm 19.07 \mathrm{pg} / \mathrm{ml}, \mathrm{p}<0.05)$ and treatment-responsive group $(270.04 \pm 23.03 \mathrm{pg} / \mathrm{ml}$ vs. $127.37 \pm 11.42 \mathrm{pg} / \mathrm{ml}, \mathrm{p}<0.05)$. The survivin level in refractory RA patients was positively correlated with the Disease Activity Score 28. Immunohistochemical analysis revealed that survivin expression was significantly higher in the synovial tissues of refractory RA patients compared to treatment-responsive patients and healthy controls.

Conclusion: The results of this study showed that survivin is overexpressed in refractory RA patients and the serum survivin level is correlated with disease activity.

Keywords: Refractory rheumatoid arthritis; surviving; apoptosis.
\end{abstract}

Rheumatoid arthritis (RA) is a multi-factorial chronic inflammatory disease, characterized by hyperplasia of synovial tissue and pannus formation, leading to joint deformity and dysfunction. As gaining a deep insight into the pathogenesis and treatment of $\mathrm{RA}$, the combination of non-steroidal anti-inflammatory drugs (NSAIDs), disease modifying anti-rheumatic drugs (DMARDs) and biologics has improved treatment effects of RA. However, there are still some RA patients who do not respond to these drugs. In such cases, it is difficult to control disease activity and progressive joint damage and dysfunction. Patients who have received formal and full course of treatment (such as combination therapy of two or more DMARDs for over half a year) without reported improvement in the condition, or recurrent condition or appearance of progressive joint destruction, are referred to as having refractory rheumatoid arthritis (RRA). ${ }^{1}$ Multiple factors may contribute to RRA, including multiple drug resistance, ${ }^{2,3}$ risk factors affecting prognosis, complications, chronic viral infections and resistance to apoptosis in fibroblast-like synoviocytes and inflammatory cells. Survivin is a new human gene encoding a structurally unique inhibitor of apoptosis proteins (IAP), apoptosis inhibitor, and plays an important role in the hyperplastic growth of tissues and tumors. Since synovial hyperplasia in RA is similar to a locally invasive tumor, many studies have showed the involvement of survivin in RA pathogenesis, ${ }^{4}$ however, there is no report about whether the expression of survivin is associated with RRA.

Received: June 25, 2013 Accepted: August 29, 2013

Correspondence: Jin Wei Chen, M.D. Department of Rheumatology, The Second Xiangya Hospital, Central South University, 0086-410011, Changsha, China.

Tel: +8613974876481 e-mail: peterh2so4@163.com

o2014 Turkish League Against Rheumatism. All rights reserved. 
The aim of this study was to evaluate the association between the expression of survivin and RRA in the Chinese Han race group.

\section{PATIENTS AND METHODS}

The experimental protocols used in this study were approved by the local ethics committee, and a written consent form was obtained from each patient included in this study. According to the 1987 criteria of the American College of Rheumatology (ACR), we enrolled 60 patients with RA, who were recruited from the outpatient and inpatient units of the Department of Rheumatology, in the Second Xiangya Hospital of Central South University. These patients were divided into three groups: 20 patients with early untreated group RA, 20 patients with good response to therapy, which was the RA treatment effective group according to the remission criteria of the ACR20, and 20 patients with bad response to therapy, those who had RA over one year and treated by DMARDs over half-year but with a still active disease. Furthermore, 20 healthy controls were participated in this study. All participants were from the Han race of China. The latter two groups of RA patients were treated by only two DMARDs (methotrexate $10 \mathrm{mg} /$ week and leflunomide $20 \mathrm{mg} /$ day) and NSAIDs (celecoxib $200 \mathrm{mg}$ as necessary) without glucocorticoids or biologics.

We collected and analyzed following demographic and clinical data of all participants from the medical records, which including age, sex, duration of disease, Disease Activity Score 28 (DAS28), erythrocyte sedimentation rate (ESR), C-reactive protein (CRP), rheumatoid factor (RF) and anticyclic citrullinated peptide antibody (ACPA).

Five milliliter blood samples of all participants were obtained from the cubital vein and directly were transferred into serum tubes. The serum was centrifuged at $3,000 \mathrm{rpm}$ for five min, aliquoted, and stored at $-80{ }^{\circ} \mathrm{C}$ until use. Then, we determined the survivin levels by a sandwich enzyme-linked immunosorbent assay (ELISA) using a pair of matched antibodies (Human survivin ELISA; R\&D Systems, USA, lot 296759). Briefly, 96-well polystyrene dishes were coated with capture antibodies and were left overnight at room temperature. Following washing, plates were blocked with phosphate buffered salinebovine serum albumin (PBS-BSA) containing $5 \%$ sucrose. Matched samples of serum were introduced into the parallel strips at a dilution of one in 10 in PBS-BSA. The horseradish peroxidase-labelled detection antibodies and the corresponding substrate were used for color development. Double-wave reading at 450 and $570 \mathrm{~nm}$ was used and the difference of absorbance was calculated. Finally, we compared the obtained absorbance values with the serial dilution of recombinant survivin and presented as picograms per milliliter $(\mathrm{pg} / \mathrm{ml})$.

Fifty-one synovium samples were obtained from the $60 \mathrm{RA}$ patients and the trauma joints of the 20 healthy control group, following joint replacement surgery or synovectomy. Specimens were fixed in $10 \%$ neutral-buffered formalin (pH 7.4) at $4{ }^{\circ} \mathrm{C}$ for 24 hours and embedded in paraffin. Four-micrometer thick tissue sections were used and dewaxed in xylene and rehydrated through decreasing concentrations of ethanol and water. Immunohistochemical staining for survivin expression was carried out using a standard immunoperoxidase technique (ABC-method). All slides were warmed up for $35 \mathrm{~min}$ to a temperature of $55{ }^{\circ} \mathrm{C}$ for dewaxing, boiled in $10 \mathrm{mM}$ citrate buffer ( $\mathrm{pH}$ 6.0) by microwave treatment $(600 \mathrm{~W})$ for $20 \mathrm{~min}$ for demasking the antigens. All stainings were performed in cover slides in combination with the prepared slides; K562 cells as positive control and one negative control were included. Once the slides with endogenous peroxidase was immersed in methanol with $0.03 \%$ hydrogen peroxide for $12 \mathrm{~min}$, endogenous peroxidase activity was blocked. The primary antibody was incubated for $30 \mathrm{~min}$ at a temperature of $37{ }^{\circ} \mathrm{C}$ (dilution 1:200, GTX100052, USA). After washing with PBS-buffer, the secondary antibody was applied at room temperature for $12 \mathrm{~min}$. The staining for survivin was visualized with the DAB kit (Beijing Zhong shan Golden Bridge Biotechnology Co., Ltd). The specimens were counterstained with hemalum. The stained specimens were viewed at an objective magnification of $\mathrm{x} 200$ and $\mathrm{x} 400$ by three investigators.

Cells stained brown were considered positive. With 50 cells per field, at least four fields were randomly observed under high magnification. 
Table 1. The clinical characteristics of the patients and the healthy control group

\begin{tabular}{|c|c|c|c|c|c|c|c|c|c|c|c|c|c|}
\hline & \multicolumn{3}{|c|}{$\begin{array}{l}\text { The healthy control } \\
\text { group }(n=20)\end{array}$} & \multicolumn{3}{|c|}{$\begin{array}{l}\text { Early untreated } \\
\text { group }(n=20)\end{array}$} & \multicolumn{3}{|c|}{$\begin{array}{l}\text { Treatment effective } \\
\text { group }(n=20)\end{array}$} & \multicolumn{3}{|c|}{$\begin{array}{l}\text { Refractory } \\
\text { group }(\mathrm{n}=20)\end{array}$} & \multirow[b]{2}{*}{$p$} \\
\hline & $\mathrm{n}$ & $\%$ & Mean \pm SD & $\mathrm{n}$ & $\%$ & Mean \pm SD & $\mathrm{n}$ & $\%$ & Mean \pm SD & $\mathrm{n}$ & $\%$ & Mean \pm SD & \\
\hline \multicolumn{14}{|l|}{ Sex } \\
\hline Male & 11 & 55 & & 5 & 25 & & 8 & 40 & & 4 & 20 & & \multirow{2}{*}{0.29} \\
\hline Female & 9 & 45 & & 15 & 75 & & 12 & 60 & & 16 & 80 & & \\
\hline Age (year) & & & $49.65 \pm 10.06$ & & & $52.35 \pm 13.48$ & & & $48.20 \pm 10.86$ & & & $54.70 \pm 13.19$ & 0.48 \\
\hline $\begin{array}{l}\text { Duration of disease } \\
\text { (month) }\end{array}$ & & & 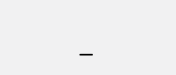 & & & $51.30 \pm 54.12$ & & & $62.40 \pm 50.14$ & & & $85.35 \pm 50.33^{*}$ & \\
\hline
\end{tabular}

The percentage of positive cells in total cells were calculated. Staining results were divided into: (i) negative (-), no significant difference between cell color and the background. (ii) Weakly positive $(+)$, positive cells $<10 \%$. (iii) Positive $(++)$, positive cells account for $10 \% \sim 50 \%$. (iv) Strongly positive $(+++)$, positive cells $>50 \%$.

\section{Statistical analysis}

All data were performed by the SPSS for Windows version 16.0 software program (SPSS Inc., Chicago IL, USA). Measurement of data which met normal distribution were expressed as mean \pm standard deviation. The skewness distribution was expressed as median (interquartile spacing); Two arbitrary sets of independent sample t-test or analysis of variance were used for the comparison of measured data for normal distribution, and homogeneity of variance; The two independent samples, Wilcoxon rank test or Kruskal Wallis $\mathrm{H}$ tests were used for skewness distribution or ordinal data, when the variance was not neat. The Kruskal Wallis $\mathrm{H}$ test was found to be statistically significant, and the Nemenyi method was used to compare the two groups. Comparison of count data between the two groups was made by the Chi-square test, and the Fisher's exact probability method. On the other hand, single factor analysis of variance (one-way ANOVA) was used for comparing multiple sample means, and the overall sense of variance analysis, for least significant difference (LSD) pairwise comparison; Pearson correlation was used for analysis of serum levels of survivin and the correlation between clinical and laboratory data. The inspection level for alpha $=0.05$.

\section{RESULTS}

The clinical and demographic characteristics of the patients are presented in Table 1 and 2 . There was no statistically significant differences in sex, age, among the four groups ( $p>0.05$ ), but the duration of disease in refractory group was statistically significant longer compared to the healthy control group, $\mathrm{t}=-2.06, \mathrm{p}<0.05$.

The ELISA test was used to measure survivin levels in the serum samples obtained from RA $(n=60)$ patients and healthy control group $(n=20)$. The levels of serum survivin in the early untreated group were significantly higher than in the healthy control group $(257.18 \pm 17.32$ vs. $116.68 \pm 19.07 \mathrm{pg} / \mathrm{ml}, \quad \mathrm{p}<0.05)$ and treatment effective group $(257.18 \pm 17.32$ vs.127.37 $\pm 11.42 \mathrm{pg} / \mathrm{ml}, \mathrm{p}<0.05)$. The levels of serum survivin in the refractory group were significantly higher than in the

Table 2. Laboratory test results in the untreated group, the treatment effective group and refractory group

\begin{tabular}{lccr}
\hline & Early untreated group & Treatment effective group & Refractory group \\
\hline White blood cell $\left(\times 10^{9} / \mathrm{L}\right)$ & $7.73 \pm 3.98$ & $6.23 \pm 2.18$ & $6.47 \pm 2.00$ \\
Rheumatoid factor $(\mathrm{IU} / \mathrm{ml})$ & $218.50 \pm 110.34$ & $223.45 \pm 92.56$ & 0.21 \\
Erythrocyte sedimentation rate $(\mathrm{mm} / \mathrm{h})$ & $60.65 \pm 37.26$ & $18.75 \pm 9.19$ & 0.64 \\
C-reactive protein $(\mathrm{mg} / \mathrm{l})$ & $31.08 \pm 13.55$ & $11.86 \pm 6.52$ & $89.85 \pm 37.66$ \\
Anti-citrullinated protein antibodies $(\mathrm{IU} / \mathrm{ml})$ & $437.70 \pm 102.92$ & $104.90 \pm 45.30$ & $57.97 \pm 21.79$ \\
\end{tabular}


Table 3. The levels of survivin in the serum among the rheumatoid arthritis patients and the healthy control group

\begin{tabular}{lcc}
\hline Groups & Cases & $\begin{array}{c}\text { Levels of survivin in the } \\
\text { serum }(\mathrm{pg} / \mathrm{ml})\end{array}$ \\
\hline $\begin{array}{l}\text { The healthy control group } \\
\text { Early untreated group }\end{array}$ & 20 & $116.68 \pm 19.07$ \\
Treatment effective group & 20 & $257.18 \pm 17.32^{* \#}$ \\
Refractory group & 20 & $127.37 \pm 11.42$ \\
$\begin{array}{l}\text { "Comparison with the healthy control group, } \mathrm{p}<0.05 ; \text { \# Comparison with } \\
\text { treatment effective group, } \mathrm{p}<0.05 .\end{array}$ \\
\hline
\end{tabular}

healthy control group $(270.04 \pm 23.03$ vs. $116.68 \pm 19.07 \mathrm{pg} / \mathrm{ml}, \quad \mathrm{p}<0.05)$ and treatment effective group $(270.04 \pm 23.03$ vs.127.37 $\pm 11.42 \mathrm{pg} / \mathrm{ml}, \mathrm{p}<0.05)$. Survivin levels did not differ significantly between the early untreated group of patients and the refractory group (Table 3, Figure 1).

The relationship between serum survivin level and clinical characteristics and laboratory test was evaluated in RA groups. In early untreated group, serum survivin levels were positively correlated with CRP $(r=0.76, p=0.00)$, but no significant correlations were found between survivin levels and age, duration of disease, RF, WBC, ESR and ACPA. In the refractory group, serum survivin levels were positively correlated with DAS28 $(\mathrm{r}=0.68, \quad \mathrm{p}=0.00) \quad$ (Figure 2a), ESR $(\mathrm{r}=0.82$, $\mathrm{p}=0.00)$ (Figure $2 b)$ and ACPA $(r=0.93, p=0.00)$. No significant correlations were found between

(a)

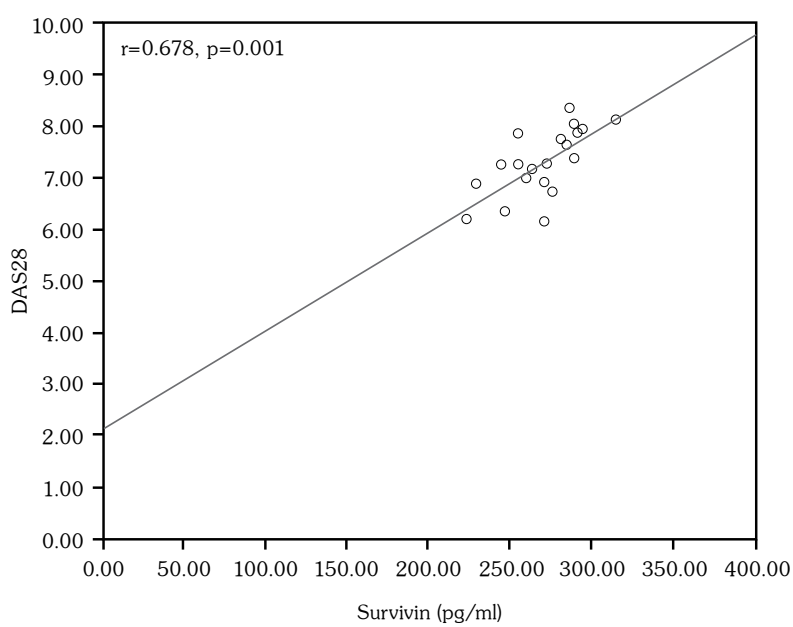

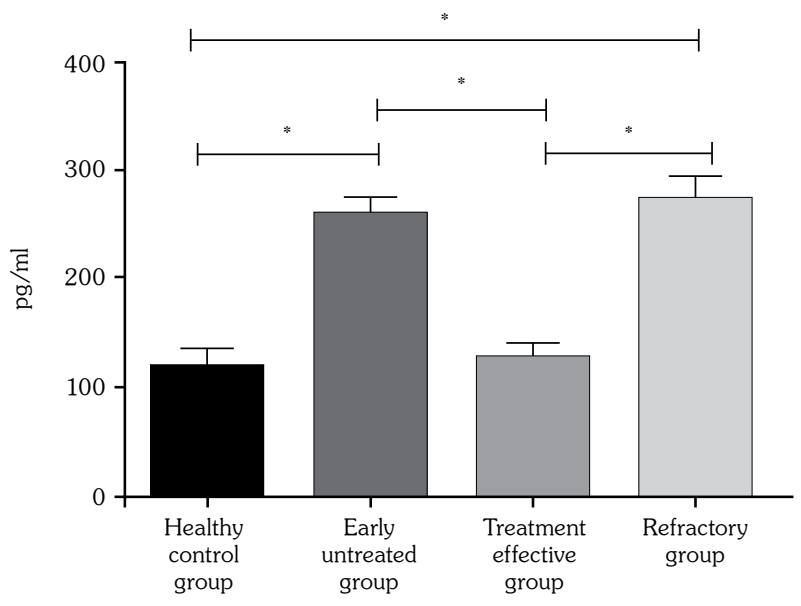

Figure 1. The levels of survivin in the serum among the rheumatoid arthritis patients and the healthy control group. * $\mathrm{p}<0.05$.

survivin levels and age, duration of disease, RF, WBC, CRP ( $p=0.80,0.13$, and 0.50, 0.75, 0.65 , respectively). There were no significant correlations between serum survivin levels and ESR, CRP, ACPA and other clinical characteristics in the treatment effective group.

Fifty-one synovial tissues were obtained from 60 patients with RA and 20 patients of the control group and were stained by immunohistochemical staining methods. The positive cases of expression of survivin in synovial tissue from the early untreated group was significantly higher than in the controls (Chi-square $=11.18, \mathrm{p}=0.00$ ) and the effective

(b)

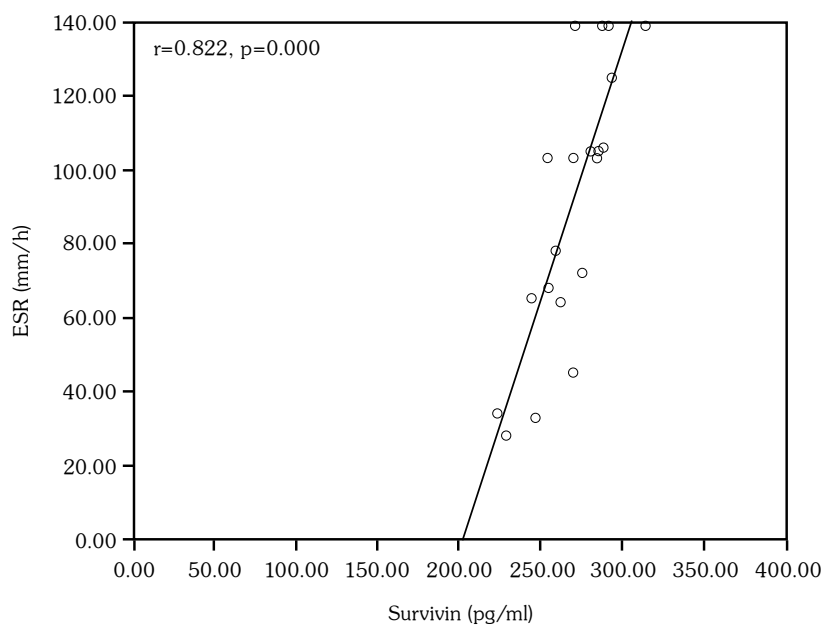

Figure 2. (a) The levels of serum survivin are positively correlated with disease activity score 28 (DAS28). (b) The serum survivin levels are positively correlated with erythrocyte sedimentation rate (ESR) in refractory rheumatoid arthritis patients. 
group (Chi-square=6.75, $\mathrm{p}=0.04$ ). The positive cases of expression of survivin of the refractory group was significantly higher than the treatmenteffective group (Chi-square $=7.10, \mathrm{p}=0.03$ ) and the controls (Chi-square $=13.93, p=0.00$ ). There was no significant difference between the refractory group and the early untreated group (Chi-square $=0.31$, $p=0.86$ ). Expression of survivin in synovial tissues from the four groups are shown in Figure 3a-d. The positive and negative controls are shown in Figure $3 e, f$. The positive cases of each group are shown in Table 4, 5 .

\section{DISCUSSION}

Refractory rheumatoid arthritis is a challenging problem in clinical practice with an underlying complex disease mechanism. ${ }^{5}$ Some evidences have pointed out that resistance to apoptosis is one of the most important factors that affects the effectiveness of RA therapy. ${ }^{6}$ Survivin is the strongest apoptosis factor ever found among IAP family. According to the studies, ${ }^{7-8}$ one of the different features of survivin which distinguishes from the general structure of mammalian IAPs
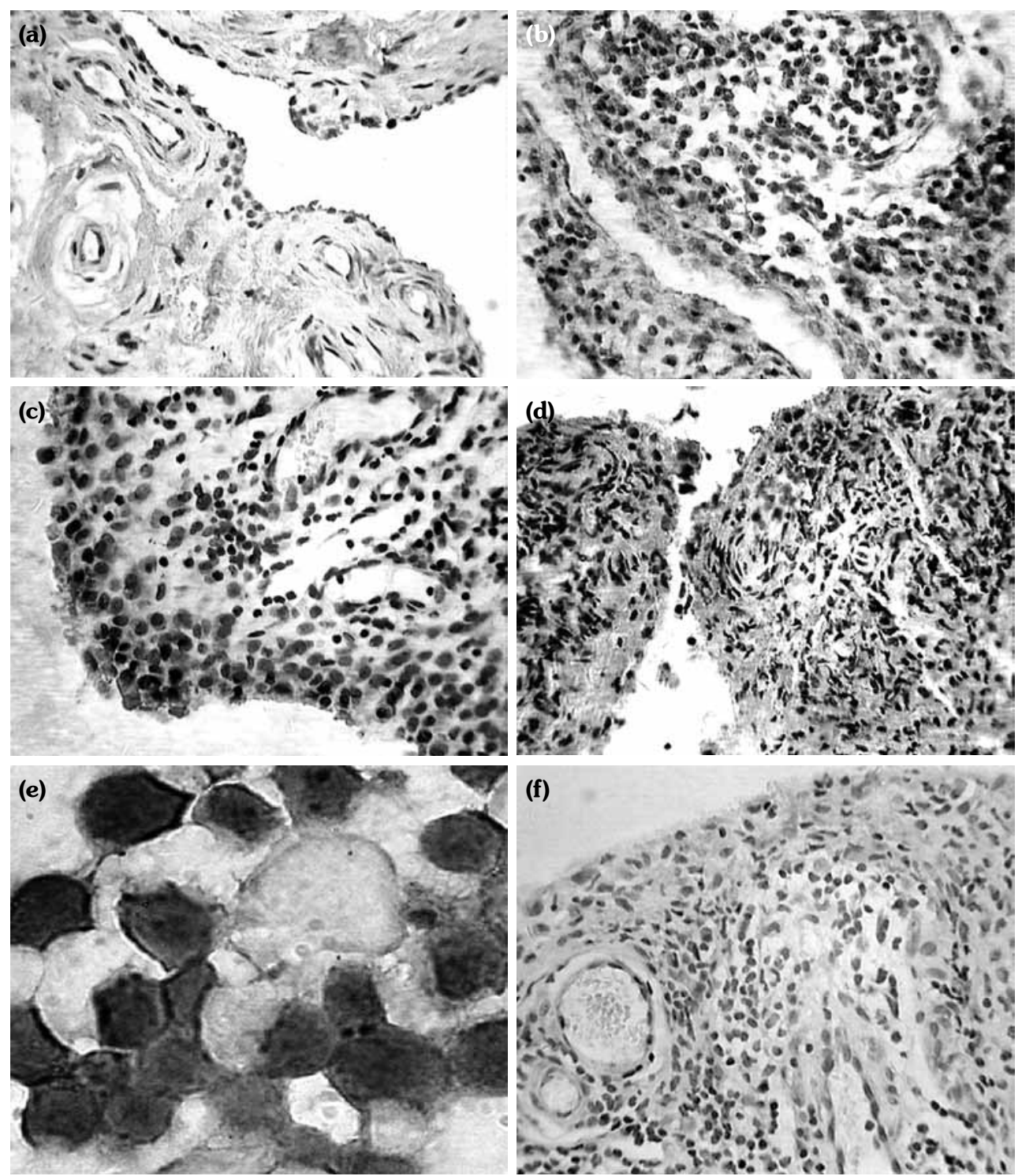

Figure 3. Immunohistochemical stain of survivin in synovial tissue of rheumatoid arthritis and the controls. (a) The healthy control group (x400). (b) The early untreated group (x400). (c) The treatment effective group (x400). (d) The refractory group (x400). (e) The positive control of K562 (x400). (f) The negative control of the inflamed synovia (x400). 
Table 4. The positive cases of survivin in the rheumatoid arthritis patients and the healthy control group

\begin{tabular}{lccccc}
\hline & \multicolumn{5}{c}{ Survivin } \\
\cline { 2 - 6 } Groups & Cases & - & + & ++ & +++ \\
\hline The healthy control group & 9 & 9 & 0 & 0 & 0 \\
Early untreated group & 18 & 4 & 6 & 6 & 2 \\
Treatment effective group & 8 & 6 & 1 & 1 & 0 \\
Refractory group & 16 & 3 & 4 & 6 & 3 \\
\hline
\end{tabular}

is the lack of a C-terminal RING finger domain and a caspase recruitment domain. Furthermore, survivin has important implications for the pathogenesis of RA and high expression of survivin is involved in a poor prognosis in RA patients. In an observational study carried out during five consecutive years, Svensson et al., ${ }^{9}$ demonstrated that the higher the expression of survivin in mononuclear cells, the more serious was the joint erosion. Bokarewa et al. ${ }^{4,10}$ found that survivin levels from RA synovial fluid were significantly higher in patients with joint damage than in patients without joint damage; DMARDs can lower the survivin level in synovial fluid. Ahn et al. ${ }^{11}$ pointed out that survivin expression in highly erosive joints was significantly higher than in non-erosive joints, and was also significantly higher than in osteoarthritis patients. In addition, survivin expression level was positively correlated with disease activity. These aforementioned studies show that survivin expression is strongly related to bone erosion in $\mathrm{RA}$.

In our study, we found that there was an overexpression of survivin in serum and synovial tissues in RA patients compared with the controls, suggesting that survivin may be involve in the pathogenesis of RA. Furthermore, our result also showed that survivin expression in the early untreated group was significantly higher than in the treatment effective group, suggesting that methotrexate and leflunomide may inhibit the expression of survivin, thereby promoting apoptosis of synovial cells. Survivin expression in the refractory group was significantly higher than in the treatment effective group and the control group, and was also found to be higher than the early untreated group, although statistically insignificant. We suggest that bone erosion may be associated with high expression of survivin, which inhibits procedural apoptosis of synovial cells and promote abnormal synovial hyperplasia
Table 5. The multiple comparison results of positive cases

\begin{tabular}{lcc}
\hline Comparison among groups & Chi-square & $p$ \\
\hline The healthy control and early untreated group & 11.18 & 0.00 \\
The healthy control and treatment effective group & 0.68 & 0.71 \\
The healthy control and refractory group & 13.93 & 0.00 \\
Early untreated and treatment effective group & 6.75 & 0.04 \\
Early untreated and refractory group & 0.31 & 0.86 \\
Treatment effective and refractory group & 7.10 & 0.03
\end{tabular}

and pannus formation. Survivin may be implicated in RRA.

Moreover, we also found that serum survivin levels in refractory group patients is associated with disease activity, probably because survivin mainly inhibits the activity of caspase- 3 and caspase-7 the terminal effector of apoptosis, or interferes in the activity of caspase-9, blocking the common pathway of cells apoptosis induced by a variety of stimuli, and leading to apoptosis tolerance, with disease activity becoming uncontrollability. In our study, the serum survivin levels were also found to be correlated with ACPA in the refractory group. However, there was no relationship in other groups, which may be due to the fact that overexpression of survivin in RRA patients prolongs survival time of synoviocyte and lymphocytes, maintaining their activation and infiltration, more easily leading to apoptosis tolerance and bone erosion, as ACPA is an important predictor of bone erosion. ${ }^{12}$ In addition, there are three NF- $\mathrm{KB}$ binding points in the promoter region of the survivin gene, which can activate nuclear factor NF- $\mathrm{KB}$ through tumor necrosis factor receptor-mediated signal transduction, thus reducing the role of NF- $\mathrm{KB}$ in protein inhibition, so that the cells are free from apoptosis. ${ }^{13}$ The basic therapeutic drugs of RA such as methotrexate are not only DMARDs, but also antineoplastic drugs. Inflammatory synovium of RA is characterized by active growth, quick metabolism, and aggressive growth, which is very similar to the characteristics of tumors.

Our study is the first study to report the overexpression of survivin in RA patients, particularly in RRA of the Chinese Han race population, and the serum survivin level which was found to be correlated with disease activity. Although the exact mechanism of the high levels of survivin in RRA has not been well 
understood, there are some reports suggesting that survivin can regulate interleukin- 6 and recruit inflammatory cells, which lead to an aggrevated inflammatory synovitis and joint destruction in RA. ${ }^{11}$ Hence, we suggest that high levels of survivin may be one of the causes leading to RRA. In addition, we assume that long-term use of methotrexate in RA patients will inhibit the proliferation of activated $\mathrm{T}$ lymphocytes and activate $\mathrm{NF}-\kappa \mathrm{B}$ at the same time to increase the expression of survivin, which leads to apoptosis resistance of the target cells during the treatment process when some patients become refractory. Therefore, down regulation of survivin expression may offer a new approach to overcome RRA.

\section{Declaration of conflicting interests}

The authors declared no conflicts of interest with respect to the authorship and/or publication of this article.

\section{Funding}

The study was supported by a grant from the National Natural Science Foundation of China (No. 81172850).

\section{REFERENCES}

1. van de Putte LB, Kroot EJ, van Riel PL. Management of refractory rheumatoid arthritis. Rheumatology (Oxford) 1999;38 Suppl 2:32-4.

2. Tsujimura S, Saito K, Nawata M, Nakayamada S, Tanaka Y. Overcoming drug resistance induced by P-glycoprotein on lymphocytes in patients with refractory rheumatoid arthritis. Ann Rheum Dis 2008;67:380-8.

3. Morgan C, Lunt M, Brightwell H, Bradburn P, Fallow $\mathrm{W}$, Lay $\mathrm{M}$, et al. Contribution of patient related differences to multidrug resistance in rheumatoid arthritis. Ann Rheum Dis 2003;62:15-9.
4. Bokarewa M, Lindblad S, Bokarew D, Tarkowski A. Balance between survivin, a key member of the apoptosis inhibitor family, and its specific antibodies determines erosivity in rheumatoid arthritis. Arthritis Res Ther 2005;7:R349-58.

5. Chen J, Chen L, Mao N, Liu Y. Association of the MDR1 3435 polymorphism in patients with refractory rheumatoid arthritis in a Chinese population. Rheumatol Int 2012;32:3127-30.

6. Isgren A, Forslind $\mathrm{K}$, Erlandsson M, Axelsson C, Andersson S, Lund A, et al. High survivin levels predict poor clinical response to infliximab treatment in patients with rheumatoid arthritis. Semin Arthritis Rheum 2012;41:652-7.

7. Deveraux QL, Reed JC. IAP family proteins-suppressors of apoptosis. Genes Dev 1999;13:239-52.

8. Mita AC, Mita MM, Nawrocki ST, Giles FJ. Survivin: key regulator of mitosis and apoptosis and novel target for cancer therapeutics. Clin Cancer Res 2008;14:5000-5.

9. Svensson B, Hafström I, Forslind K, Albertsson K, Tarkowski A, Bokarewa M. Increased expression of proto-oncogene survivin predicts Joint destruction and persistent disease activity in early rheumatoid arthritis. Ann Med 2010;42:45-54.

10. Bokarewa M, Tarkowski A, Magnusson M. Pathological survivin expression links viral infections with pathogenesis of erosive rheumatoid arthritis. Scand $\mathrm{J}$ Immunol 2007;66:192-8.

11. Ahn JK, Oh JM, Lee J, Bae EK, Ahn KS, Cha HS, et al. Increased extracellular survivin in the synovial fluid of rheumatoid arthritis patients: fibroblast-like synoviocytes as a potential source of extracellular survivin. Inflammation 2010;33:381-8.

12. Lequerré T, Richez $\mathrm{C}$. Anti-cyclic citrullinated peptide antibodies in rheumatoid arthritis: the best diagnostic tool but also a great interest in prognosis. Rev Prat 2012;62:1088-9.

13. Che XF, Zheng CL, Owatari S, Mutoh M, Gotanda T, Jeung $\mathrm{HC}$, et al. Overexpression of survivin in primary ATL cells and sodium arsenite induces apoptosis by down-regulating survivin expression in ATL cell lines. Blood 2006;107:4880-7. 